\title{
VAULTED STRUCTURES IN THE ARCHAEOLOGICAL PARK OF POMPEII: 3D SURVEY AND MONITORING
}

\author{
D. Verde ${ }^{1, *}$ \\ ${ }^{1}$ DiARC, Università degli Studi di Napoli “Federico II" - daria.verde@ unina.it
}

Comission II - WG II/8

KEY WORDS: Masonry vaults, Pompeii, Great Pompeii Project, 3D survey, Laser-scanning, Monitoring

\begin{abstract}
:
The contribution focuses on the relationship between preventive conservation and digital technologies, with particular attention to the Archaeological Park of Pompeii and its masonry vaults. These fragile macro-elements, both for their intrinsic condition of ruins and for their historical vulnerability to seismic stress, were detected through a careful 3D survey, in the context of the Great Pompeii Project (GPP). The analysis was carried out in 2015 with laser-scanning technology and photogrammetry, and was aimed at the knowledge, documentation and measurement of conditions of degradation or instability. On the basis of a deep knowledge, supported by in situ investigations, it was possible to define the most appropriate conservative interventions for vaulted structures. Also, the interpretation of the vulnerabilities and of the causes of degradations phenomena allowed focusing on the program phase, in order to maintain the benefits of restoration over time. Moreover, the contribution anticipates how these surveys will be integrated by a doctoral research with industrial characterization. This research is currently being conducted in close relationship with Tecno In - a leading company in the field of knowledge and diagnostics of cultural heritage - and its object is the experimentation of innovative techniques for diagnostics, preventive conservation and restoration of the vaulted structures of Pompeii. Therefore, in the comparison with the surveys realized in 2015 lies the opportunity of deepening the understanding and of monitoring the evolution of degradation conditions of the vaulted buildings under exam.
\end{abstract}

\section{INTRODUCTION}

The issues related to the conservation and enhancement of archaeological areas nowadays represent one of the most discussed topics in the international debate. Addressed by several disciplinary points of view, this field of study is characterized by a multitude of meanings, determining at the same time its complexity and richness. At the center of the theme of the implementation of knowledge, conservation and maintenance of archaeological areas and cultural sites, there is also a notion of great relevance in contemporary culture, namely that of "cultural heritage" as "public asset", to be preserved as an identity place for the members of a community.

The protection, restoration and enhancement of archaeological areas represent, in fact, themes that require a broad disciplinary approach - including the fields of architecture, archaeology, geophysics and structural engineering, just to name a few - to be pursued also thanks to the fundamental contribution of innovative digital technologies. However, these objectives must be achieved using the specific knowledge of Conservation, intended as the necessary framework for all these contributions.

Therefore, the conceptual framework is that of Conservation, and particularly the assumptions typical of the Italian tradition, which have determined significant theoretical advances throughout the 20th century. Moreover, in the last decades the culture of conservation has deepened its multiple and complex disciplinary aspects, in terms of historical, methodological and operational approach. Therefore, nowadays it is not possible to avoid an interdisciplinary method, necessary in order to make correct design choices. It is necessary to experiment on the field the possibility of combining the need to preserve the identity characteristics of built heritage with that of its safety, especially in a territory such as the Italian and Campania region, affected by seismic events and hydrogeological problems (Picone, Russo, 2018).

Being a systemic problem, conservation of built cultural heritage requires a complex strategy that can be characterized as "planned and preventive" when it is understood as a process. In fact, it consists in a transition from exclusively operational interventions to a process of study and control. This kind of processes is particularly necessary for the conservation of archaeological structures, because they need to be preserved interfering as little as possible with their authenticity.

Although the theme of prevention and maintenance in the field of conservation of monuments and sites is gaining attention, it is not a recent assumption. In fact, the concept of Preventive Conservation for built heritage, which is argued to improve its preservation at large, has been recently developed exploiting the idea of prevention itself from the medical field (Van Balen, 2015).

As such, it must be conceived not just as an abstract model, but as a practical possibility, in order to provide effective answers to the problem of maintaining our built heritage in use. In fact, from an organizational and operational point of view, maintenance activities, especially when implemented according to suitable strategies, can maximize results in terms of preservation and enhancement of archaeological structures, as they avoid or minimize the increase of damage (Gasparoli, 2012).

\footnotetext{
* Corresponding author
} 


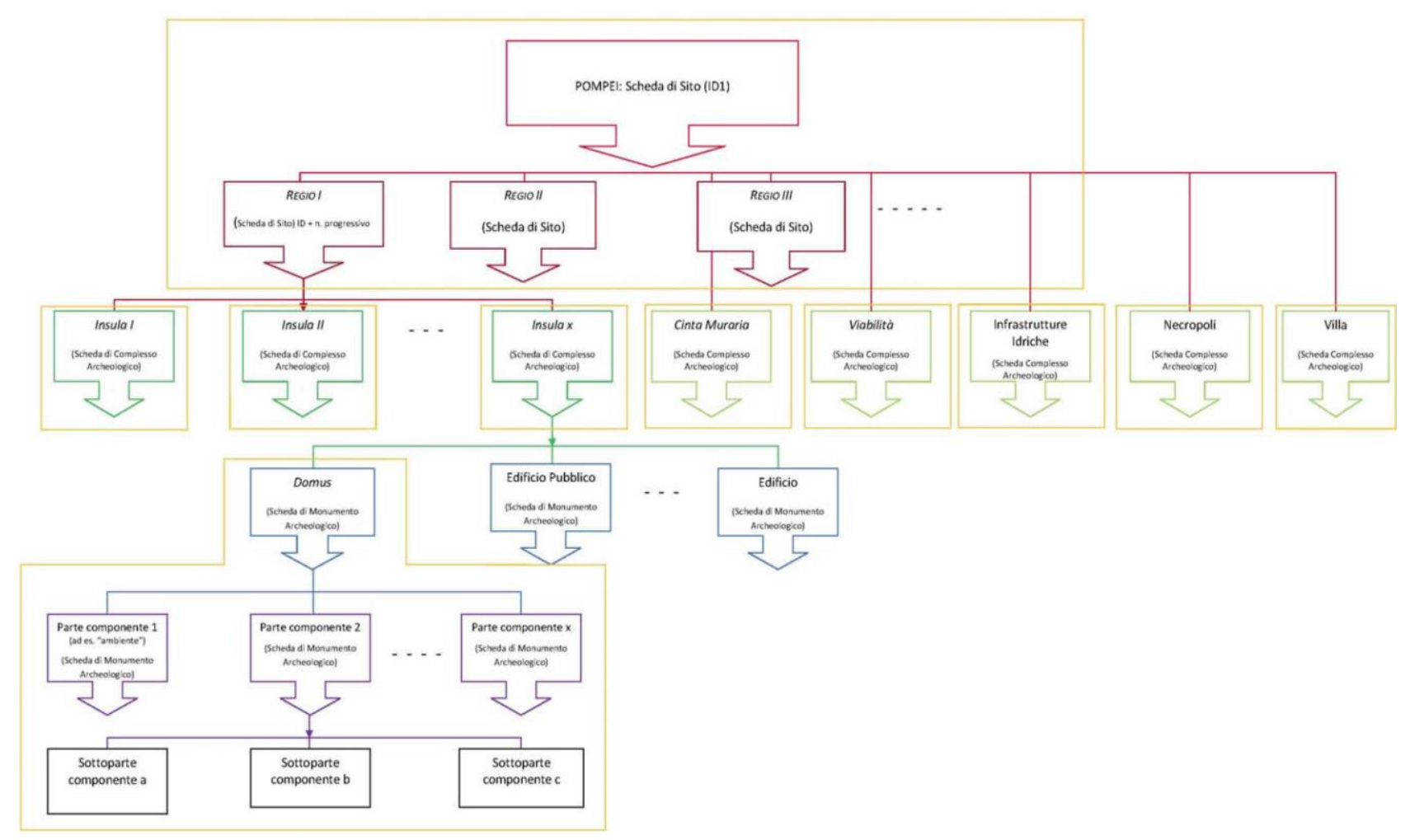

Figure 1. Logical scheme of the GPP Information System (Technical annex SI-GPP).

In Italy, planned preventive conservation has found, at a legislative level, initial acknowledgment with the Cultural Heritage and Landscape Code 42/2004. In the part concerning restoration (art. 29), the Code introduces the notion of preventive and planned conservation of artistic heritage as a radically innovative element that substantially changes the previous protection activity ${ }^{1}$. In this sense, the Code has certainly provided meaningful guidelines. However, these guiding principles need further experimental investigation, so that maintenance practices may not have the only objective of modifying the physical structure of heritage, but are meant as a complex operation that aims at maximizing the permanency of structures and materials, limiting their deterioration as far as possible, so as to maintain the benefits of restoration and enhancement of cultural heritage over time.

In other terms, the mindset related to preventive conservation requires a radical change of our attitude towards heritage: the focus is on the program phase that requires the identification of the needs as well as the assessment of the state of conservation of buildings (Della Torre, 2016; 2018).

As stated by the Franceschini Commission ${ }^{2}$ already over fifty years ago, conscious preservation can only be based upon a careful knowledge of cultural heritage and its state of conservation. It is therefore clear that one of the primary goals of planned preventive conservation lies precisely in its capacity

1 The new Code of Cultural Heritage and Landscape (D.lgs. 42/04 e s.m.i.), promulgated on the 22nd January 2004, states that «Cultural Heritage conservation is guaranteed through coherent, coordinated and planned activities of study, prevention, maintenance and restoration». According to the definition given by the Code, prevention «means the set of activities useful to limit the situations of risk concerning cultural property in its context».

2 Law n.310/1964 instituted an Inquiry Commission for the preservation and valorization of cultural, archaeological, artistic and landscape heritage. This Commission, known as the Franceschini Commission from the name of its chairman, concluded its findings in 1967. to produce knowledge. This includes not only the gathering of technical data, but also a profound understanding of the historic singularity of existing buildings, achievable with the investigative attitude typical of archaeologists. Furthermore, the deep knowledge at the base of this approach is also the best antidote against the risk of inducing a loss in heritage authenticity, as it enhances the designer's awareness, orienting the project towards more compatible and conservative solutions.

\section{THE ARCHAEOLOGICAL PARK OF POMPEII: A CASE STUDY}

As is known, the ancient city of Pompeii - listed has a World Heritage Site in 1997 - represents the best preserved city of Roman times. Buried under a layer of ashes and lapilli during the eruption of Vesuvius in 79, it was rediscovered at the end of the 16th century. However, its exploration began only in 1748, at the behest of Charles III of Bourbon, and continued systematically throughout the 19th century. Today, the archaeological area of Pompeii extends for about 66 hectares, about 45 of which have been excavated. Being the third most visited state museum site in Italy, the city and its exceptional heritage of architecture, sculptures, paintings, mosaics still represent one of the best testimonies of Roman life.

Therefore, the archaeological park of Pompeii is in many ways a somewhat extraordinary case study: not only for its documentary, symbolic, historic and artistic nature, but also because of the organizational, procedural and managerial tools that have been tested with an innovative approach. In fact, in Pompeii the theory of preventive conservation has been translated into a regularly carried out maintenance under constant supervision of the scientific staff. Here the innovative strategies developed in recent years to promote the preservation and valorization of cultural heritage have generated efficient applications, which have in turn led to scientific contributions and useful guidelines (Osanna, Rinaldi, 2018). 


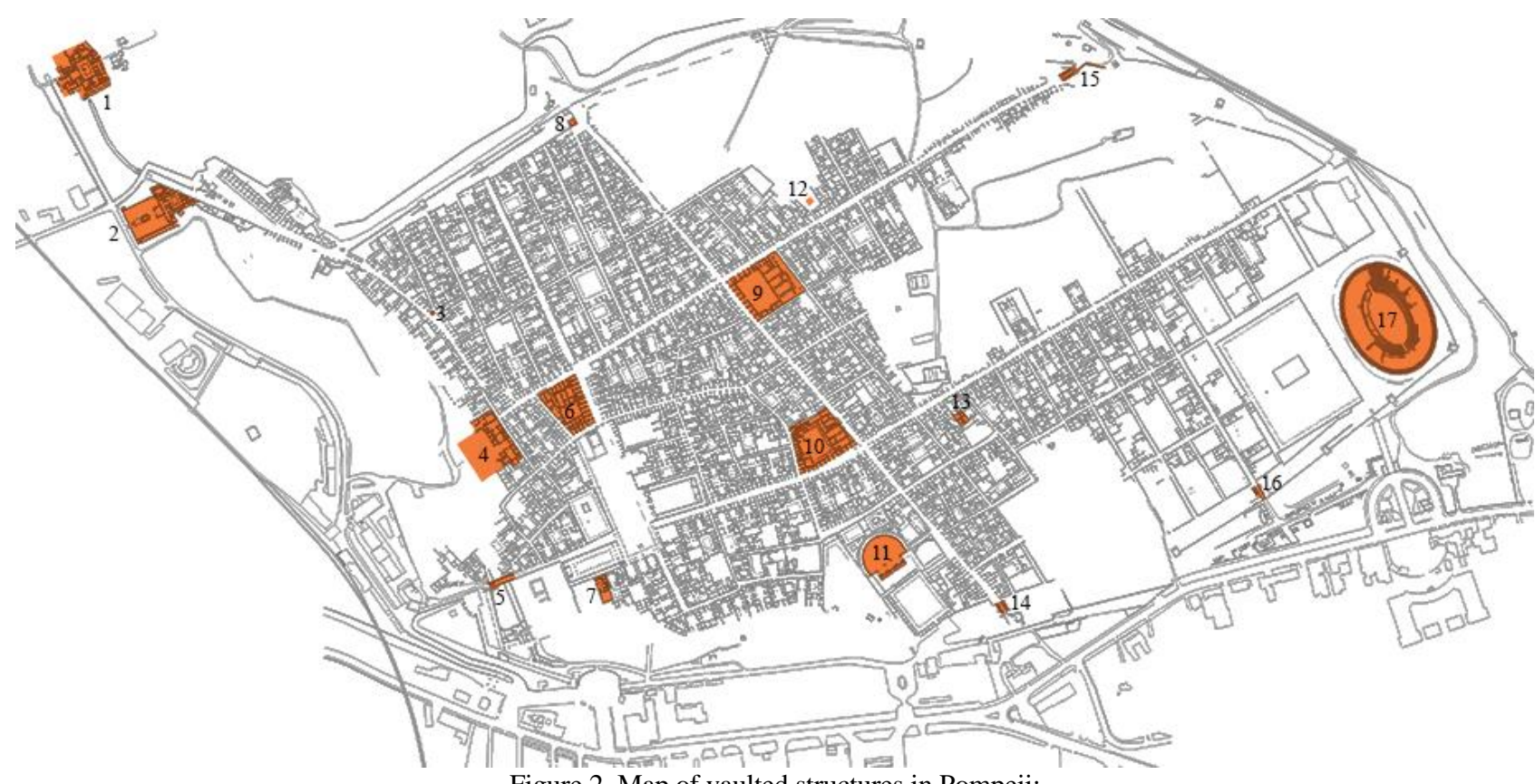

Figure 2. Map of vaulted structures in Pompeii:

1. Villa of the Mysteries, 2. Villa of Diomede, 3. Public well, 4. House of Marcus Fabius Rufus, 5. Marina Gate, 6. Forum Baths, 7. House of Championnet, 8. Castellum Acquae, 9. Central Baths, 10. Stabian Baths, 11. Large Theatre, 12. Public well, 13. House of the Cryptoporticus, 14. Stabia Gate, 15. Nola Gate, 16. Nocera Gate, 17. Amphitheatre.

\subsection{The Great Pompeii Project}

In recent years, a series of dramatic episodes and the effects of a progressive widespread degradation - consequence of years of poor attention to routine maintenance - brought Pompeii back into the spotlight as a negative example of heritage protection and management. In particular, in November 2010, the collapse of the 'Schola Armaturarum' generated enormous media attention on the Vesuvian city, finally making it clear to Italy and to the whole world that a large part of the archaeological area was in a serious state of degradation.

In this climate and for these reasons, the 'Great Pompeii Project' (GPP) was undertaken in 2012, thanks to the work of Giovanni Nistri, at the time General Manager of the GPP, alongside the Superintendent, today Director of the Archaeological Park of Pompeii, Massimo Osanna. This extraordinary project, funded by the European Union, has made it possible to tackle many long-standing problems, such as the mitigation of hydrogeological instability and the consolidation of excavation fronts. Furthermore, a large part of the archaeological site has been secured, many areas have been restored and reopened and, above all, a project of planned maintenance has been launched, with the aim of overcoming the extraordinary nature of the Great Pompeii Project (Nistri, Osanna, 2014; Osanna, 2018; Osanna, Picone, 2018).

One of the most relevant aspects of the Great Project is that it has approached the ancient city as a single entity. In fact, since the archaeological site cannot be preserved if not within its environment - climatic conditions and exposure to earthquakes - it has been dealt with as a complex system, whose fragility is both global and local. Therefore, restoration and conservation works have not focused exclusively on individual houses, but have also included vast areas of the city, with a considerable improvement of the conservational status of the entire site.
Specifically, the Great Project was divided into five Plans, each declined into specific actions ${ }^{3}$. Among these, the Knowledge Plan was of fundamental importance for conservation purposes, because it laid the foundations for the scientific study and monitoring of degradation phenomena. Its implementation has allowed a correct identification of critical issues, as well as of structural and restoration problems, representing an action of systematic knowledge extended to all the 'insulae' of the archaeological park. Moreover, the survey, investigation and diagnosis campaigns, carried out between 2015 and 2016, used the most innovative digital methodologies in order to provide analytical data on the state of conservation of the buildings. In particular, the use of laser scanning technology and photogrammetry allowed the development a new geo-referenced map of Pompeii in 1:50 scale and a three-dimensional documentation of large portions of the city.

The huge amount of data and information acquired is currently being organized in the GPP Information System (SI-GPP), a flexible multimedia database linked to a geo-referenced cartography. This tool represents the technical and scientific premise not only for the conclusion of the Pompeii Project, but also for the implementation of a long-term planned and preventive conservation methodology (Figure 1). In other words, all the information and data collected in the Knowledge Plan converge into a unique digital tool for the entire Vesuvian city, thus allowing monitoring the conditions of its buildings over time. In this aspect lays the originality of the approach pursued in Pompeii.

The five Plans included in the GPP are the Knowledge Plan, the Works Plan, the Plan for the Use and for the Improvement of Services and Communication, the Safety Plan and the Technological Enhancement and Capacity Building Plan. 
Moreover, since information and data are increasing considerably over time, the use of an Information System offers the possibility to manage them in dynamic mode, enabling a continuous updating and filing and, above all, supporting decision making (Della Torre, Moioli, Pili, 2018). In other words, the oncoming Information System not only constitutes the reference point for the planning of all maintenance, restoration and archaeological investigation, but also aims at collecting the 'corpus' of knowledge of the ancient city. Therefore, it will be accessible - simply and quickly - both by the Superintendence and the specialists responsible for the preservation of the archaeological park, and by the whole scientific community in need of information for the purpose of archaeological research. Thanks to the architecture of the Knowledge Plan, the case of Pompeii demonstrates how technology is not far from the world of archaeology, but constitutes its indispensable ally.

\subsection{Vaulted structures in Pompeii}

Undoubtedly, since its discovery, the site of Pompeii has always represented a rich laboratory on the theme of the restoration and conservation of archaeological heritage. Due to the terrible natural disaster that transformed the rich Campania town into a city buried alive, Pompeii has in fact fortunately for us - become a museum of Roman civilization, providing us with countless examples of the construction techniques and the principles described by Vitruvius (Adam, 1981, 1988). Within this extremely rich architectural heritage, the vaulted structures of the ancient city constitute a document of great importance, as they allow - thanks to the survival of their roofs - to acknowledge and fully appreciate the spatial configuration of important complexes (Figure 2).

In Roman construction methods laid the possibility of creating large covered spaces, whose realization was made possible precisely by the use of vaulted structures. This ability to solve the problem of covering vast spaces constituted, in fact, the main expression of Roman architecture: a spatial expression, given by the massiveness of dimensions and the harmony of spaces. The scheme of Roman vaults covering large rooms is therefore so essential that it constitutes the main characteristic of construction and spatial architecture of the entire Imperial period (Giovannoni, 1925; Marta, 1991).

In particular, the truly typical system of Roman architecture was that of concrete vaults, that is to say vaulted structures made of casting material, which, once set, equals a real artificial monolith (Lancaster, 2005, 2015). This technique was used to create generally very simple geometric shapes (barrel, cross or spherical vaults) ${ }^{4}$. Moreover, these constructions were usually characterized by the presence of elaborate surfaces, such as external coverings, frescoes and stuccos, whose presence, by hiding the structural elements, does not allow a full understanding of the architectural and structural behavior of the vaults.

\footnotetext{
Some of the earliest traces of the use of this technique, whose diffusion dates to the 2nd century BC, are found in Rome and Pompeii itself: i.e. the vaults of the Porticus Emilia in Rome (about 174 BC), those of the sanctuary of Fortuna Primigenia in Preneste (about 110 BC) and those of the Stabian Baths in Pompeii (second half of the second century $\mathrm{BC}$ ).
}

\subsection{Methodology}

Given these premises, it is particularly interesting to dwell on the state of the art related to the knowledge and interpretation of Pompeian case studies, fragile macro-elements both for their intrinsic condition of ruins and for their historical vulnerability to seismic stress. As part of the GPP Knowledge Plan, they were detected through a careful 3D survey, carried out with laser-scanning technology and photogrammetry, and aimed at the documentation of conditions of degradation or instability in order to define the most appropriate conservative interventions (Aicardi et al., 2019; Previtali, Valente, 2019).

Therefore, the methodology adopted was inductive and was based on direct observation, focused on the mapping and characterization of degradation phenomena. At the same time, the study of indirect sources (bibliographic, iconographic, and documentary) was carried out, in order to compare the results and develop the appropriate numerical models. The ultimate goal was the definition of possible orientations, guiding criteria and operational strategies for the conservation of archaeological heritage of architectural, historical-artistic and constructive importance.

\subsection{D survey and monitoring}

The investigation conducted within the GPP has been carried out, along with orthophotos and mapping of degradation, by several Italian universities. The survey and diagnosis works were in fact divided into 6 different lots, along the limits of Pompeian Regiones ${ }^{5}$. As part of these works, carried out in 2015 and partially updated in 2016, plans and sections of all the buildings in the archaeological area (including vaulted structures) were developed in scale 1:50.

As regards the $3 \mathrm{D}$ surveys, they were conducted using laser scanner technology in the House of the Cryptoporticus, the Amphitheater, the Central and Stabian Baths, while photogrammetry was used for the Forum Baths and the entire Regio VIII, including the Large Theatre and the Championnet Complex. As imaginable, the documentation thus acquired was of fundamental importance for the orientation of the conservation and restoration choices.

In this sense, the case of the Forum Baths - particularly relevant for the rare Pompeian application of the vaulted constructive system - is emblematic (Figure 5). Here, the careful on-field investigations, carried out together with an archival and iconographic research, have made it possible to reconstruct the history of the three main rooms of the men's department. In fact, despite having been entirely vaulted for more than a century with homogeneous and consistent roofing in terms of geometry and materials, these spaces are actually the result of a complex combination of persistence and restoration. As a matter of fact, at the time of the excavations (conducted between 1823 and 1824), in each of the three rooms only the terminal part of the vaults had survived. Hereafter their reintegration was carried out in a mimetic manner, with the shapes and geometries that the original monument was supposed to have and using archaeological material present 'in situ' (Mangone, 2016).

\footnotetext{
The first lot includes Regio I; the second includes Regio II and the Western suburb; lot 3 includes Regio III, IV, V and IX, while lot 4 concerns Regio VI and lot 5 concerns Regio VII; finally, the sixth
} lot focuses on Regio VIII. 


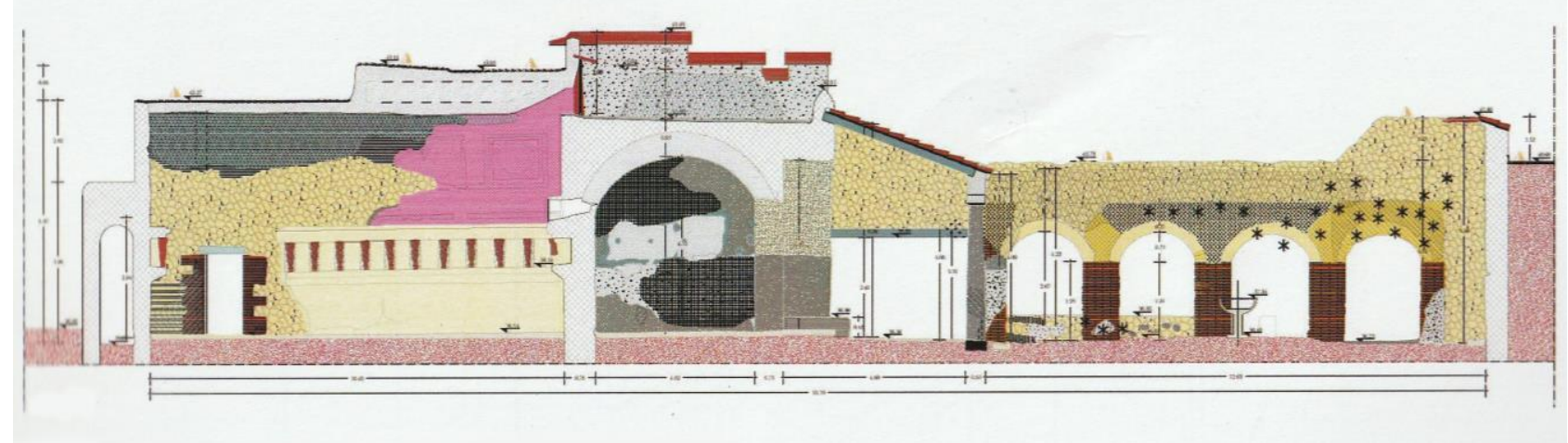

Figure 3. Forum Baths, longitudinal section with the analysis of the state of conservation of stone surfaces (Cicirelli, Brancaccio, Mangone, 2018).

The careful photogrammetric survey carried out through the use of a drone (Figure 4) has therefore allowed identifying physical traces of this history. In fact, on the extrados of the roofs which appear homogeneous in the geometry of the intrados there are some almost imperceptible signs that document the various construction and reconstruction phases, as well as the use of valuable techniques now obsolete, such as the beaten lapillus. The awareness of the different phases, derived from the careful survey (Cicirelli et al., 2018), allowed to preserve these traces, thus orienting the choices of the waterproofing project of the roof, whose necessity had been shown by the analysis of the state of conservation of stone surfaces (Figure 3 ).

Similarly, in the House of the Cryptoporticus (Figures 6, 7 and 8 ), the survey of the traces of vaulted structures in the thermal rooms led their consolidation and restoration, guiding their spatial reconfiguration. The latter was therefore re-proposed with the construction of a barrel vault and a cross vault made of laminated wood elements ('praefurnium'), and a barrel vault in plasterboard in room 20 ('frigidarium'), all characterized by a unmistakable modernity. These restorations, respectful of the authenticity of the building, on the one hand facilitate the understanding of ancient spaces and, on the other, do not interfere with the ancient walls, both in terms of static behavior and formal language (Cicirelli, Previti, Tabone, 2018).

\subsection{Results}

On the basis of a deep knowledge, supported by 'in situ' investigations, it was possible to define the most appropriate conservative interventions. Also, the interpretation of the vulnerabilities and of the causes of degradations phenomena, derived from the careful survey and the comparison with indirect sources, allowed to focus on the program phase, in order to maintain the benefits of restoration over time. Moreover, once the information acquired (and that related to recent interventions) has been inserted into the Informative System, an influx of all future data will be guaranteed by indepth and continuous comparison with the building system, along with supervision of its state of conservation. This will allow, for the first time, a computerized basis with comparative elements, related to a precise historical moment, thereby contributing to the creation of the "medical record" of the monument, an essential tool for the management of future conservation.

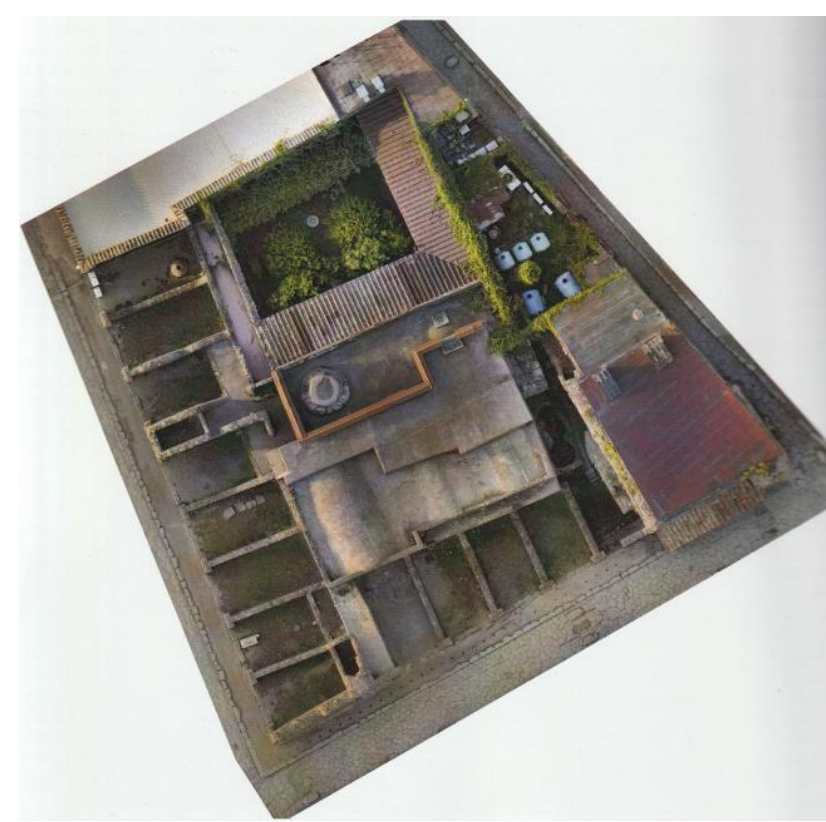

Figure 4. Forum Baths, orthophoto of the extrados of the roofs carried out through the use of a drone (Cicirelli, Brancaccio, Mangone, 2018).

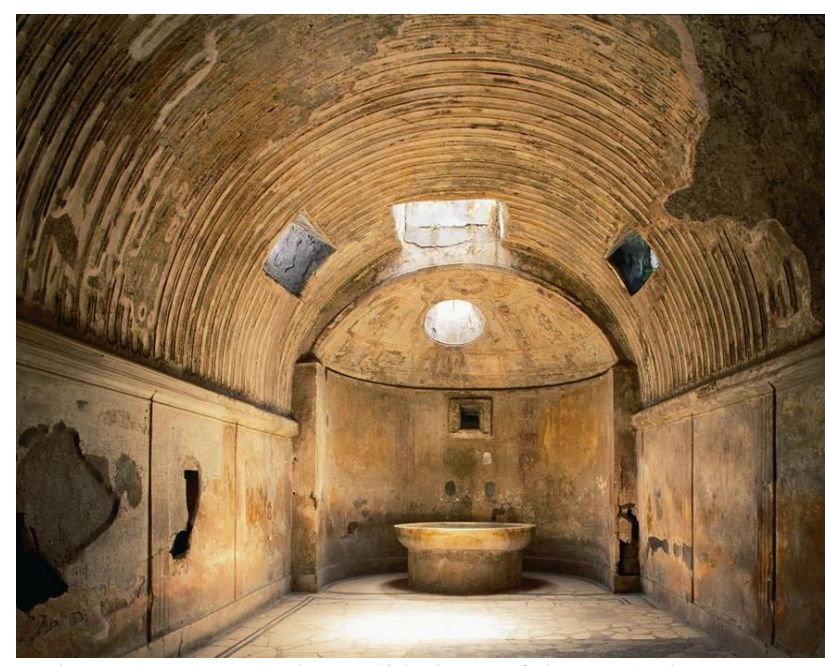

Figure 5. Forum Baths, 'calidarium' of the men's department roofed by a concrete barrel vault covered with stucco. 


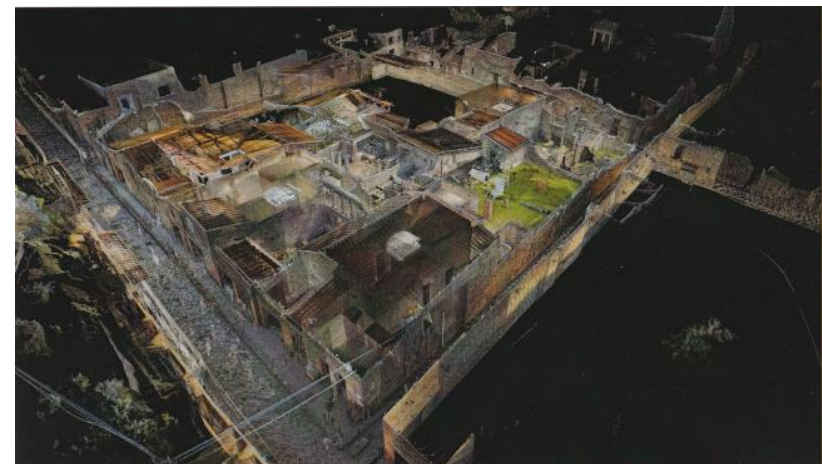

Figure 6. Regio I, insula 6, 3D survey conducted using laser scanner technology and photogrammetry (Osanna, 2018).

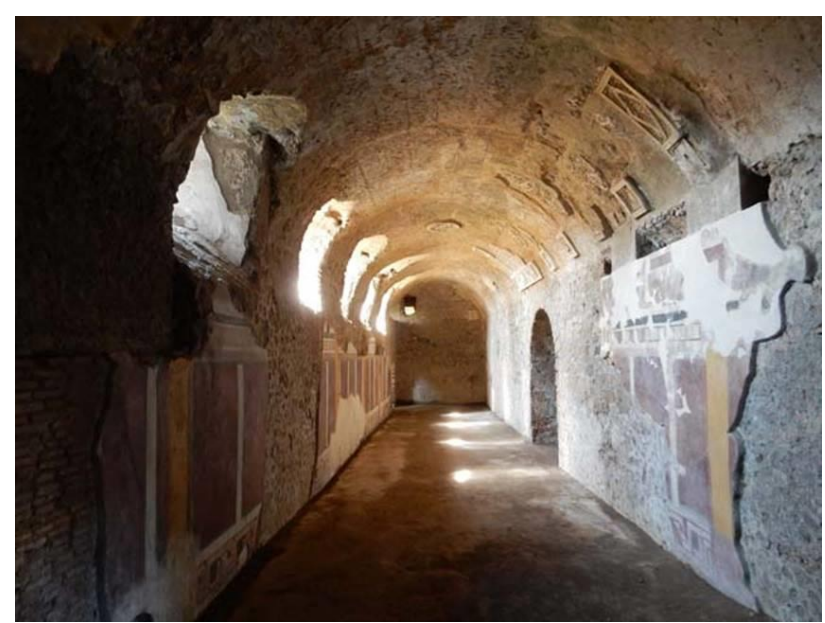

Figure 7. House of the Cryptoporticus, large indoor corridor roofed by a concrete barrel vault covered with frescoes.

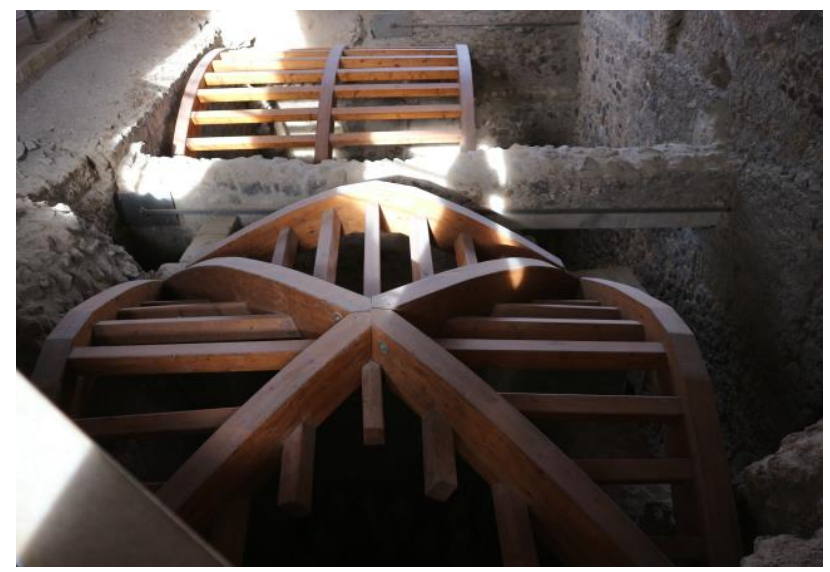

Figure 8. House of the Cryptoporticus, 'praefurnium' roofed with a barrel vault and a cross vault made of laminated wood.

The primary aim of this work is to promote a change in perspective and favor a view of monitoring as a diagnostic tool, and of maintenance as a daily and constant 'curative' activity. In fact, until today, the greatest obstacle standing in the way of identifying the most appropriate maintenance techniques is precisely due to the scarcity of information regarding many great conservational works undertaken in the past. The consequence is that reconstructing the anamnesis of the archaeological monuments, repeatedly worked on in the past, is extremely difficult. By implementing a process of systematical collection of all the information available on a building within a database, it is possible to plan maintenance interventions and start a management process that in the medium and long term would lead to a significant reduction in $\operatorname{costs}^{6}$. In this sense, what was accomplished in the GPP can be considered an approach truly oriented towards preventive conservation, in which the cognitive phase represents a crucial moment.

\section{CONCLUSIONS}

In light of the international resonance that the conservation of the Archaeological Park of Pompeii has assumed thanks to the implementation of the Great Project, the doctoral research conducted by the author aims at the experimentation of innovative techniques for diagnostics, preventive conservation and restoration of the vaulted structures of Pompeii. This research with industrial characterization is being carried out in close relationship with Tecno In - a leading company in the field of knowledge and diagnostics of cultural heritage - and in continuity with the interdisciplinary themes at the center of the $\mathrm{PhD}$ in Architecture of the University of Naples Federico $\mathrm{II}^{7}$. The research project pursues the objective of combining the instances related to the knowledge and cataloging of the rare surviving vaulted structures on the site with those of preventive conservation and architectural restoration. This must necessarily be accompanied by an investigation on historical construction processes, which in fact constitute a field of research that is particularly significant for its effects on contemporary conservation and risk prevention strategies, especially in highly seismic contexts such as the Campania region ${ }^{8}$.

Next to a study aimed at the knowledge of conservation and restoration works undertaken in Pompeii and on the basis of recent surveys conducted within the framework of the Knowledge Plan, we will proceed to the selection of the Pompeian case studies object of diagnostic experiments and structural modeling. This study phase will include a careful analysis carried out in the field, together with a new 3D survey of the selected case studies. These graphic reconstruction will constitute an indispensable integration of the documentation realized within the GPP, both if the surveys where made using traditional techniques only (as in the case of the Western Suburb, of the 'Insula Occidentalis' and of the city walls), and if innovative three-dimensional restitution techniques were already used. In fact, in both cases, the comparison with the surveys realized five years ago gives the opportunity of monitoring the evolution of degradation conditions. At the same time, they represent the basis for the material-constructive study of Pompeian vaults, in relation to their vertical structures and surface plasters.

6 Similar results are currently being obtained with other methods, for example HBIM that is being used for preventive conservation (Amato, Sorrentino, 2018).

It is in fact fully consistent with themes already addressed in research projects of the SSD ICAR / 19 (Restoration), among which: Enhancing Pompeii. Pompeii between the archaeological site and the modern town. Knowledge, restoration and enhancement of the Insula Occidentalis (University program 2017, Scientific Director: prof. R. Picone); Invisible / Accessible. Masonry domes of the 15th and 16th centuries in Campania. Innovative strategies for the interpretation and the multi-thematic inclusive fruition of vulnerable architectures (University program 2017, Scientific Director: prof. V. Russo); Pompei accessibile. Linee guida per una fruizione ampliata del sito archeologico (FARO 2010, Scientific Director: prof. R. Picone).

8 Among structural risks, seismic risk for masonry structures has been investigated by huge literature, leading to sound knowledge and developing retrofitting techniques. 
The proposed approach is therefore characterized by the integration of well-established methodologies with innovative strategies for the understanding of structures that are not totally visible, thereby perpetrating a concept of integrated diagnostics, merging humanistic and technical-scientific knowledge (Aveta, 2017). The project aims at the definition of a cognitive method for the interpretation of the ancient building site of Pompeii and its vaulted structures, combining bibliographic and archival research and direct data from on-site explorations with 3D surveys, together with an understanding of the problems related to present use. At a closer look, through this methodology one can overcome isolated and partial understandings of historical and constructive information, in order to reach a unitary understanding of archaeological heritage that is a fundamental requirement for planned preventive conservation.

\section{REFERENCES}

Adam, J. P., 1988. L'arte di costruire presso i romani (materiali e tecniche), Milan.

Adam, J. P., Adam, T., 1981. Le tecniche costruttive a Pompei. Una documentazione a cura del CNRS, in Pompei 1748-1980. I tempi della documentazione, Rome.

Aicardi, I., Chiabrando, F., Lingua, A. M., Noardo, F., 2018. Recent trends in cultural heritage $3 D$ survey: the photogrammetric computer vision approach, in «Journal of Cultural Heritage», n. 32, 257-266.

Amato, L., Sorrentino, A., 2018. La diagnostica integrata: dalla conoscenza alla gestione dei beni culturali, in Picone R., Russo V. (eds.), L'arte di costruire in Campania tra restauro $e$ conoscenza strutturale, Clean, Naples, 305-313.

Aveta, A., 2017. Conoscenza integrata e tecnologie informatiche per il restauro e la fruizione di Castel Nuovo, in Aveta A. (ed.), Castel Nuovo in Napoli. Ricerche integrate e conoscenza critica per il progetto di restauro $e$ di valorizzazione, Artstudio Paparo, Naples, 30-43.

Cicirelli, C., Brancaccio, F., Mangone, F., 2018. Le Terme del Foro dalla conoscenza al restauro, in Osanna, Picone, 2018, 293-309.

Cicirelli, C., Previti, M., Tabone, G. P., 2018. Il restauro della casa del Criptoportico, in Osanna, Picone, 2018, 265-279.

Della Torre, S., 2016. Planned preventive conservation and the structural performances of buildings, in Van Balen K., Verstrunge E. (eds.), Structural Analysis of Historical Constructions - Anamnesis, diagnosis, therapy, controls, Conference proceedings (Leuven, 13-15 settembre 2016), CRC Press, London, 147-150.

Della Torre, S., 2018. The management process for built cultural heritage: preventive systems and decision making, in Innovative built heritage models, in Van Balen K., Vandesande A. (eds.), Innovative Built Heritage Models and Preventive Systems, Conference proceedings (Leuven, 6-8 settembre 2017), CRC Press, London, 13-20.

Della Torre, S., Moioli, R., Pili, A., 2018. Digital tools supporting conservation and management of built cultural heritage, in Van Balene K., Vandesande A. (eds.), Innovative Built Heritage Models and Preventive Systems, Conference proceedings, CRC Press, London, 101-106.
Gasparoli, P., 2012. La manutenzione preventiva programmata del patrimonio storico come prima forma di valorizzazione, in «Techne. Journal of Technology for Architecture and Environment», n. 3.

Giovannoni, G., 1925. La tecnica della costruzione presso $i$ Romani, Rome.

Lancaster, L. C., 2005. Concrete vaulted construction in Imperial Rome. Innovations in context, Cambridge University Press, Cambridge.

Lancaster, L. C., 2015. Innovative vaulting in the architecture of the Roman empire. $1^{\text {st }}$ to $4^{\text {th }}$ centuries CE, Cambridge University Press, New York.

Marta, R., 1991. Tecnica costruttiva romana, Kappa, Rome.

Mangone, F., 2016. Un laboratorio di restauro dell'Ottocento: le Terme del Foro, in Mangone F., Immaginazione e presenza dell'antico. Pompei e l'architettura di età contemporanea, Artstudiopaparo, Naples, 123-153.

Monego, M., Menin, A., Fabris, M., Achilli, V., 2019. 3D survey of Sarno Baths (Pompeii) by integrated geomatic methodologies, in «Journal of Cultural Heritage», n. 40, 240246.

Nistri, G., Osanna, M., 2014. Valorizzare e proteggere i parchi archeologici: il caso Pompei, in Un capolavoro chiamato Italia. Un racconto a più voci di un patrimonio da tutelare, proteggere e valorizzare, Rome, 99-116.

Osanna, M., 2018. Pompei al tempo del Grande Progetto. 20122018, in Osanna, Picone, 2018, 99-130.

Osanna, M., Picone, R., 2018. Restaurando Pompei. Riflessioni al margine del grande progetto, «L'Erma» di Bretschneider, Rome.

Osanna, M., Rinaldi, E., 2018. Planned conservation in Pompeii: complexity and methodological choices, in «Journal of Cultural Management and Sustainable Development».

Picone, R., Russo, V., 2018. Un'eredità per il futuro. Le ragioni di una ricerca, in L'arte di costruire in Campania tra restauro e conoscenza strutturale, Clean, Naples, 11-15.

Previtali, M., Valente, R., 2019. Archaeological documentation and data sharing: digital surveying and open data approach applied to archaeological fieldworks, in «Virtual Archaeology Review», n. 10, 17-27.

Van Balen, K., 2015. Preventive Conservation of Historic Buildings, in «International Journal for Restoration of Buildings and Monuments», n. 21 (2-3), 99-104. 